\title{
ERRATUM
}

H. H. Taylor • N. L. C. Ragg

\section{The role of body surfaces and ventilation in gas exchange of the abalone, Haliotis iris}

Published online: 30 November 2005

(C) Springer-Verlag 2005

\section{J Comp Physiol B (2005) 175:463-478.}

Unfortunately, in the published version of the article, Fig. 12 was incorrect. Here is the correct version of Fig. 12:

Fig. 12 Oxygen partial pressures $\left(P_{\mathrm{O}_{2}}\right.$, Torr $)$ observed in the haemolymph of the aorta, circum-pallial vessel and pallial vein of $H$. iris shortly after cannulation (stressed) and following $24 \mathrm{~h}$ recovery (resting)

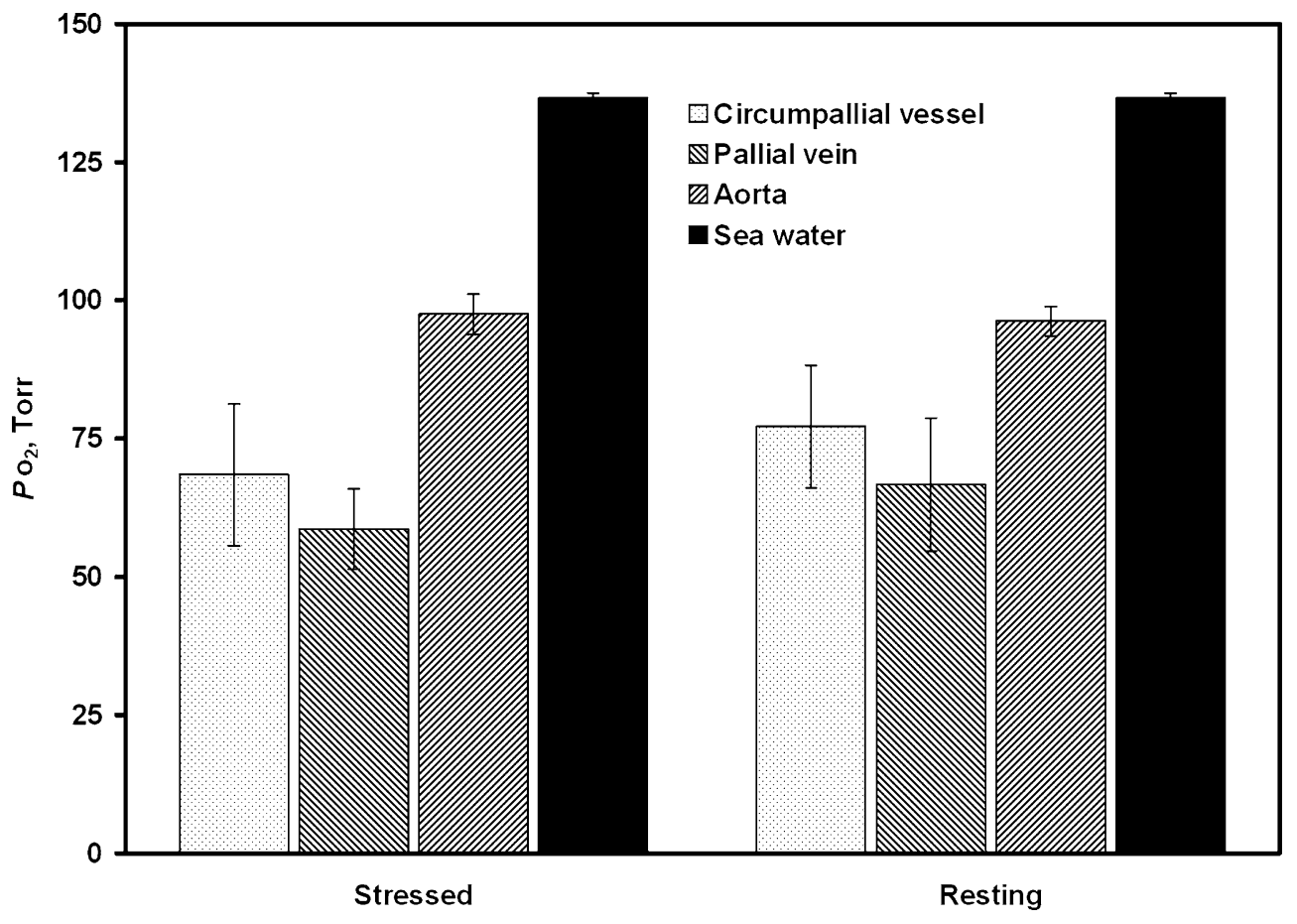

The online version of the original article can be found at http:// dx.doi.org/10.1007/s00360-005-0006-2

H. H. Taylor $(\bowtie) \cdot$ N. L. C. Ragg

School of Biological Sciences, University of Canterbury,

Private Bag 4800, Christchurch 8004, New Zealand

E-mail: harry.taylor@canterbury.ac.nz

Tel.: + 64-3-3642861

Fax: + 64-3-3642590 